\title{
The Impact of Chongqing Population Size and Structure on Carbon Emissions:A Study base on STIRPAT Model
}

\author{
HONG, Yeying \\ School of Ethnology and Sociology \\ Guizhou Minzu University \\ Guiyang City in Guizhou Province, China \\ Chongqing Fuling School of Administration \\ Fuling district in Chongqing, China \\ Email:hyeying123@163.com
}

\begin{abstract}
Such old Industrial bases in Chongqing, the aim of this paper to explore the Population change on the influence of Carbon emissions, and on the basis of the adjustment of energy structure is put forward the corresponding strategic measures.On the basis of the Time Series Data from 1996 to 2016 in Chongqing, using Econometric analysis method, Mainly to explore the Population Size, Population Urbanization rate, Aging rate, Per capita consumption, Carbon emissions intensity and the relationship between Carbon emissions and carry on the Empirical analysis. The results show that:(1) Driving force of the Population size of Carbon emissions is most significant, that Carbon emissions in Chongqing there is a close relationship with Population growth;(2)And the Carbon intensity of Population Urbanization as The second and Third driving force, the per capita consumption is affected;(3) Population aging rate was not significant statistically, but what is certain is aging degree will inevitably influence on Carbon emissions. Therefore, we need to pay attention; (4) The miniaturization of family Size has inhibitory effect on long-term Carbon emissions. In this paper, the main innovations were that: (1) Select industrial city of Chongqing as a case which has certain representativeness; (2) Include demographics, as an important index in STIRPAT Model Empirical Analysis.
\end{abstract}

Keywords-Carbon emission; Population size; Population structure; STIRPAT Model;Chongqing

\section{INTRODUCTION}

The fact of Global Warming caused by Emissions of $\mathrm{CO}_{2}$ has been a cause of the international community attaches great importance to and has become the focus of attention. According to the Netherlands Environmental Assessment Agency (PBL) and the European commission's joint research center jointly issued the trend of global $\mathrm{CO}_{2}$ emissions in 2012 report shows that China is now the world's largest $\mathrm{CO}_{2}$ emitter. Therefore, seek low Carbon development path, the lowCarbon economy is an important strategic moves to curb Global Warming. At present, the domestic and foreign scholars on Population, economic and other factors on Carbon emissions affect a lot of work, and achieved some results. Such as: Anqing Shi [1] using IPAT model, from 1975 to
1996 in 93 countries of the world's data to study the effect of Population increase on Carbon emissions, which estimates global Carbon emissions at the stage of Population scale change of elasticity coefficient of 1. 42. Guo-zhi li et al. Study on the [2] points out that the Population's impact on the environment is a two-way street: on the one hand, the pressure on resources, Population growth increases the energy consumption led to environmental degradation. Peng xizhe, etc. [3] Study Population urbanization led to the increase of Carbon emissions, Wang Qinchi [4] study Population aging degree from low to high, the resulting "demographic dividend" to reduce or disappear, and exerted a great push to curb Carbon emissions. Comprehensive the above research results, many studies from the Angle of the macroeconomic impact factors such as Population, structure of the Carbon analysis and qualitative analysis, lack of necessary data support and indepth study. In addition, compared with the economy is relatively developed eastern cities, this kind of old industrial bases in Chongqing to explore the influence of demographic factors on Carbon emissions change, and the adjustment of energy structure accordingly put forward the corresponding strategic measures have important practical significance, at the same time the results for the western region has strong demonstration significance. At the same time, the main greenhouse gas, $\mathrm{CO}_{2}$ as a kind of to achieve $\mathrm{CO}_{2}$ emission reduction is the key of the response to climate change; And to achieve the $\mathrm{CO}_{2}$ emission reduction, we must clarify factors such as Population, economic and technology influence on $\mathrm{CO}_{2}$ emissions, as this will related to $\mathrm{CO}_{2}$ emission reduction measures and strategy. Therefore, on the basis of western karst mountainous area of Carbon emissions in Chongqing as the research object, using the environment load model (IPAT), on the basis of the demographic factors into the STIRPAT model, based on the analysis to explore factors such as Population, economy, technology level, on the basis of the environmental impact of proposed some strategies to realize low Carbon economy in Chongqing, at the same time, research results with similar background area has a certain reference value.

Sponsors: This work was sponsored by the 2017 Chongqing Social Sciences Planning Youth Project [ 2017QNSH20] and Guizhou Minzu University of Doctoral Fund [2016MDBSSXM02]. 


\section{RESEARCH METHODS AND DATA SOURCES}

\section{A. Research methods}

1) Environment load model is put forward in the $1970 \mathrm{~s}$, Ehrlish (IPAT model), then Dietz, etc. Based on the stochastic model (STIRPAT) of proportion of Population and Carbon emissions of the change of the influence factors were studied, the model is that:

$$
I=C P^{\alpha} A^{\beta} T^{\chi} e
$$

From Type (1) of environmental load, C said constants, P said Population scale, A said economic level, T said technical factors, respectively, $\partial$ said the elasticity coefficient of Population, $\beta$ said economic technology, $\chi$ said the random error term, assume that can replace completely between elements. So, $\partial+\beta+\chi=1$. This is $a$ nonlinear model of multivariable, easy to study, considering the presence of heteroscedasticity and possibility, at the same time after taking logarithm for temporal data does not affect the relationship between the variables. Therefore, (1) Nonlinear production function on both sides of the exponential, converted into linear function form, get the model as follows:

$$
L n I=\alpha(\operatorname{Lnp})+\beta(\operatorname{Ln} A)+\chi(\operatorname{LnT})+\operatorname{Lne}
$$

2) In order to study the impact of Population size on Carbon emissions. So at the same time, which combining with the Chongqing data such as data availability, scientific principle, this paper add Population structure analysis of the influence of factors on Carbon emissions, the Population structure, age structure, urban and rural structure, family structure) is extended (2) type model, the model for:

$$
\begin{gathered}
L n I=C+a 1 L n P S+a 2 L n P U+a 3 L n P O+a 4 L n P F+\beta L n A+ \\
\chi L n T+L n e
\end{gathered}
$$

From Type(3), I said the environment load, with Carbon emissions, said unit for wan t; C said constant term; PS expressed as total Population, with the Population of permanent residents, said unit for ten thousand people; PU said the Population urbanization rate, the unit is \%; $P O$ said Population age structure, by ageing rate [5], unit for \%; PE said family size, unit/door; A for economic level, with per capita consumption, said unit for Yuan. $T$ said technical factors, using Carbon intensity, said unit for $\mathrm{T}$ Carbon/ten thousand Yuan GDP; Random error term line said. Among them, $a_{1}, a_{2}, a_{3}, a_{4}, \beta, \chi$ represent the Carbon emission elasticity coefficient with each of the variables.

\section{B. Data sources and processing}

\section{1) The calculation of Carbon emissions data}

For Carbon emissions data, at present China's statistical agency not released $\mathrm{CO}_{2}$ emissions data, but can be by the amount of energy consumption by the estimation of coefficient of Carbon emissions. At the same time, which given the current global $\mathrm{CO}_{2}$ emissions by $95.3 \%$ from fossil fuels, this article is to hydropower, nuclear power and other new energy Carbon emission can be neglected, mainly inspects the fossil energy of Carbon emissions. Therefore, this article on the calculation of Carbon emissions from $\mathrm{xu}$ national Carbon emissions calculation method [6] research, namely according to all kinds of energy consumption in Chongqing is multiplied to calculate their Carbon emissions coefficient. Its formula is:

$$
C_{i t}=\Sigma E_{i j t} \times F_{j}
$$

Among them, the $\boldsymbol{C}_{\boldsymbol{i t}}$ is expressed as the province of the first year of $\boldsymbol{t} \mathrm{I} \mathrm{CO}_{2}$ emissions, $\boldsymbol{E}_{\boldsymbol{i j t}}$ is expressed as the province the first $\boldsymbol{F}_{\boldsymbol{j}}$ t years of energy consumption, $\boldsymbol{F}_{\boldsymbol{j}}$ : first $\boldsymbol{j}$ of energy coefficient of Carbon emissions.

\section{2) The source of data and instructions}

To explore Chongqing since Population scale and Population structure impact on Carbon emissions, selection for period 1996-2016, Research of PS were resident Population (ten thousand people), PU for Population urbanization rate (\%), The PO for the aging rate (\%), PF for Family size (person/home), A is the per capita consumption (RMB), $\mathrm{T}$ for Carbon intensity (Carbon/T ten thousand yuan GDP) as the explained variable and interpreted variable (I) for the relationship between the total Carbon emissions (T). In addition to the above variables, there are many variables may affect the level of $\mathrm{CO}_{2}$ emissions, such as energy structure, industrial structure, the residents' consumption way and so on, but consider the research emphasis of this article, so choose Population size, Population structure, economic level and technical level is analyzed. To eliminate the price factors influence on economic variables, economic variable in 1990 as the base into a comparable price calculation. Analysis and research the Index data are from the Chongqing statistical yearbook (1997-2016), The 2016 statistics bulletin of the Chongqing economic and Social development and public publications, and on the basis of the data. (Due to space limit, therefore omitted in table).

\section{POPULATION SIZE, STRUCTURE, EMPIRICAL STUDY OF THE IMPACT OF CARBON EMISSIONS}

\section{A. Model construction and inspection}

Based on load model in environment such as Dietz (IPAT Model) based on Stochastic Model (STIRPAT) related theory, the influence of Carbon emissions measurement model was constructed. According to the basis of the data, formula (2) the multiple regression analysis model, USES the Eviews6. 0 analysis software to carry on the least squares (OLS) for processing, to eliminate the dimension and the effects of different orders of magnitude, the logarithmic processing data in Table 1. The calculation results are shown in Table1.

TABLE I. EACH VARIABLE REGRESSION COEFFICIENTS AND TEST RESULTS

\begin{tabular}{cccl}
\hline Item & Regression coefficient & The standard deviation & T-value \\
\hline LnPS & 3.402 & 1.145 & $2.971 * *$ \\
LnPU & 1.263 & 0.28 & $4.505 * * *$ \\
LnPO & 0.015 & 0.079 & 1.189 \\
LnPF & -0.696 & 0.455 & $-3.531 * *$ \\
LnA & 0.411 & 0.086 & $4.783 * * *$ \\
LnT & 1.131 & 0.102 & $11.038 * * *$ \\
C & -27.161 & 9.736 & $-2.789 * *$ \\
\hline \multicolumn{4}{r}{}
\end{tabular}


F-value $=4223.384^{* * *}, \mathrm{R}^{2}=0.999$, Adjust $\mathrm{R}^{2}=0.999$, $\mathrm{DW}=1.1813$

See through Table 1, the model fitting effect is good,which has good significance. Above all to establish the regression equation:

$$
\begin{aligned}
& L \mathrm{n} I=-27.161+3.402 L n P S+1.263 L \mathrm{n} P U+0.015 L n P O \\
& -0.696 L n P F+0.411 L n A+1.131 L n T
\end{aligned}
$$

Statistical results show that the model fitting is in good condition, correction $\mathrm{R}^{2}$ and high F-value is bigger also, DW values show that random error term does not exist autocorrelation, each variable present significant at the $10 \%$ level. Judge, according to the environmental load model (IPAT model) based on extended stochastic model (STIRPAT) is significant in statistics. From Table1 results show that Carbon emissions in Chongqing and the Population size, Population urbanization, aging Population, family size, per capita consumption, Carbon emissions intensity have significant effect, the elastic coefficient are: 3. 402, 1. 263, 0. 015, 1. 263, 0. 411, 1. 131.

\section{B. Model and explained}

Model fitting results show that with Carbon emissions influence as follows: Population size $>$ Population Urbanization level $>$ Carbon emissions intensity of Population Urbanization > Consumption per capita $>$ Family size.

1) PS coefficient is 3. 402, which indicates that the degree of Population scale effect on Carbon emissions in Chongqing, the largest of each $1 \%$ increase in Population size, can make the region's overall Carbon emissions by $3.402 \%$. Of Chongqing in past, since the amount of permanent Population grown from 1997 in 28.734 million to 2016 in 29.70 million, the net increase of 966400 people, the Population average annual growth rate of $0.21 \%$. Chongqing is located in the southwest karst mountain area, however, is still in the less developed and underdeveloped mountainous area, Population density and absolute number is larger, these will be the main factor of Carbon emissions in Chongqing pressure [7]. According to the scholars Birdsall [8] study Population growth impact on greenhouse gas emissions are two ways: on the one hand, more people more and more demand for energy, the greenhouse gas emissions also more and more; On the other hand, the rapid Population growth led to the forest destruction, changed the way of land use, etc. , all these lead to the increase in greenhouse gas emissions.

2) PU coefficient is 1.260 , which indicates that Population urbanization rate increased by $1 \%$, can make the Carbon emissions by $1.263 \%$. Since the crown, the Chongqing urban and rural Population structure has changed significantly, from $31 \%$ in 1997 to $58.34 \%$ in 2016, increased by $27.34 \%$, the average annual growth of $1.70 \%$. Results show that the urbanization process to speed up the result in the increase of Carbon emissions in Chongqing, along with the urbanization level, will also unceasingly to enhance residents' consumption level, this will bring the rigid demand for Carbon emissions, thus to promote the growth of Carbon emissions. Mainly manifested in two aspects, one is in along with the urbanization process is accelerated, urban infrastructure and residential construction to the widespread use of raw materials such as steel, cement and auto transport, such as the use of fossil fuel combustion emissions of Carbon dioxide in the process of greatly increased; Second, urbanization brings people's production and lifestyle changes, especially the use of middle fuels such as coal makes people more pressure on resources and environment from urban residents' consumption.

3) $T$ coefficient is 1.131, shows that whenever the Carbon intensity by $1 \%$ and causes a $1.131 \%$ increase in Carbon emissions in the area. In 1996-2016, Chongqing Carbon intensity from $1.698 \mathrm{t}$ Carbon/Carbon ten thousand Yuan GDP dropped to $1.1247 \mathrm{t} /$ ten thousand Yuan GDP, a drop of 0.573 t Carbon/ten thousand Yuan GDP (see chart 1). For the lower Carbon intensity shows that the higher the efficiency of economic activities, also the less $\mathrm{CO}_{2}$ emissions, but also reflect the technology level of development. However, Chongqing Carbon intensity is higher than the national average, is with the Chongqing industrial area, especially the regional dominance of heavy industry (2012, heavy industry output value accounts for $72.630 \%$ of the gross value of industrial output.), including for the use of coal as a share is higher, larger base of energy consumption, high economic growth bring huge energy consumption to a certain extent, masked by the technological progress's contribution to the inhibition of Carbon emissions. In 2012, the total energy consumption of 82.849 million tons of standard coal, coal consumption accounted for $66.640 \%$ of the total energy consumption.Therefore,technological innovation will continue to be the city one of the main methods of inhibition of Carbon emissions in the future.

4) A coefficient is 0.411 , shows that whenever the per capita consumption increased by $1 \%$, can make the Carbon emissions by $0.411 \%$. Demographic factors such as Population size, Population structure on the impact of Carbon emissions mainly in the field of Population consumption Carbon emissions. Consumption per capita in 1996 from 1734.18 Yuan to 15191.14 Yuan in 2016 (in terms of comparable price in 1990), growth 8.760 times the average annual growth rate of $14.520 \%$ (see chart 1 ). Model fitting results show that the improvement of residents' consumption and Carbon emissions growth correlation is higher, to a certain extent, increased the demand for energy consumption, resulting in the increase of Carbon emissions.

5) $P O$ coefficient was not significant statistically, it shows that the short-term fluctuations in Population age structure on Carbon emissions Rapid aging process in theory, to some extent, increased the endowment services for elderly people, health care, etc. into the resulting increase with the increase of energy consumption with aging degree. This conclusion and scholars Zhu Qin [9], Chen Jing [10] similar results, the influence of the aging of China's Carbon emissions may not be significant or it is not clear. The aging of many research results also show that the effects of energy use and Carbon emissions mechanism is very complex, and it will lead to increase or decrease of energy consumption and Carbon emissions is not clear. But what is certain is the Chongqing aging will inevitably influence on Carbon emissions, so you need to pay attention. 
6) $P F$ coefficient is 0.696 , which indicates that the influence of family size on Carbon emissions has negative effects. 1997-2016, Chongqing residents Family size from 3. 39 / person to 2. 75 households/person, a drop of 18 . $89 \%$, household number growth reached 35. 98\%, higher than the same period $1.94 \%$ of the total permanent Population growth. Family size shrink will lead to the Family the total number of households. Therefore, faster growth, Family Population growth faster than at the end of the total number of households increased, at the same time together with Family size miniaturization is the increase of the total number of households, the core Family and Family have a synthetic overlay effect on the Carbon emissions. So, choose Family number variable unit rather than the Population as a Population, the Population change on the elastic coefficient of Carbon emissions growth will increase. Therefore, for the miniaturization of family size is accelerated to a certain extent promote the expansion of the size of the residents' consumption and household consumption scale effect weakened.

\section{CONCLUSION AND DISCUSSION}

Using extension STIRPAT model, Uses the Eviews6. 0 analysis software to carry on the least squares (OLS) which regression analysis affecting the Carbon emissions in Chongqing Population scale, structure, economy and technology, related factors in the empirical analysis, the conclusion is as follows:

1) The Population size for Carbon emissions in Chongqing has significantly positive influence. Although Chongqing since the implementation of family planning, birth rate has been at the lower level, the natural Population growth rate also showed a trend of decline. But the absolute number of annual Population growth is still relatively large, so the Population size is Carbon emissions is one of the most important driving factor. The scholar Jiang research pointed out that global Population growth and the growth of energy consumption and Carbon emissions are synchronous consistent conclusions.

2) Population structure has important effects on Carbon emissions in Chongqing. One is the Population urbanization rate of Carbon emissions impact has a positive effect in second place side by side, should be considered the current urbanization impact on Carbon emissions. Therefore, we suggest that the government can through optimizing the structure of energy consumption and improving energy efficiency, adjust the industrial structure, energy conservation and environmental protection industry, using new technology to improve the land and resource utilization scale effect, slow Carbon emissions. The second is an ageing Population impact on Carbon emissions is not statistically significant, but what is certain is aging will inevitably influence on Carbon emissions, thus requiring attention. Third is the family size has negative effects on Carbon emissions, and many research results show that family size miniaturization, core is conducive to Carbon reduction. Therefore, the government should pay attention to the family structure miniaturization trend should be the important factors affecting Carbon emissions attention, at the same time increase the propaganda low Carbon family consumption patterns and consumption concept of promotion.
3) The per capita consumption of Carbon emissions influence over aging rate and the influence of family structure on Carbon emissions. Domestic demand is the principal means of government stimulus, in today's diversified consumption mode, not only expect to reduce the effect of the residents' consumption to achieve emission reduction. Therefore, need the government to formulate relevant policies to guide residents' green consumption, advocate the consumer to green, low Carbon sustainable consumption mode.

4) The Carbon intensity of the impact of Carbon emissions intensity is bigger. To show that technical progress factor's influence on Carbon emissions in Chongqing has a positive effect, to a certain extent with the theory, but it doesn't deny the impact of technological progress on Carbon emission reduction. Therefore, we suggest that the government increase the technological transformation, and improve the clean production technology, Carbon capture and sequestration technologies, etc. , So as to realize the quality of Carbon emissions.

5)After Chongqing in the national economic and social development level, but the development potential of low Carbon economy is great. Therefore, the government strengthen the energy conservation and emissions reduction, improve the efficiency of resource use, at the same time, based on low Carbon technology and system innovation development strategic emerging industries and clean energy, accelerate industrial structure adjustment and change the way of the development of Chongqing. To effectively control the influence of demographic factors on Carbon emissions growth.

\section{ACKNOWLEDGMENT}

This work was sponsored by the 2017 Chongqing Social Sciences Planning Youth Project [2017QNSH20] and Guizhou Minzu University of Doctoral Fund ;AND Dr Was "Service of the National Special Demand Talent Cultivation Project Southwest ethnic areas of Social management" results.

\section{AUTHOR IN BRIEF}

HONG, Yeying, male, People in Shucheng City of Anhui Province, China; Doctoral student of Guizhou Minzu University, lecturer, Chongqing Fuling School of Administration; Mainly engaged in Economics of Population and Social policy research direction in ethnic minority areas. E-mail:hyeying123@163. com

\section{REFERENCES}

[1] SHI AQ. The impact of Population pressure on global carbon dioxide emission, 1975-1996: Evidence from pooled cross-country data [J]. Ecological Economics, 2003(44). (In Chinese).

[2] Li Guozhi, Li Zongzhi. The Impact of Population, Economy and Technology on Carbon Dioxide Emissions- A Study Based on Dynamic Panel Model[J]. Population Studies, 2010(3). (In Chinese).

[3] Peng Xizhe Zhu Qin. Impacts of Population Dynamics and Consumption Patternon Carbon Emission in China[J]. Population Studies, 2010(1).

[4] Wang Qinchi. A Study of the Nonlinear Relationship between Population and Carbon Emissions[J]. Population Studies, 2011(1). (In Chinese). 
[5] LIU Hui-huang, LI Zi-hao. The Relationship between Chinese Population Aging and $\mathrm{CO}_{2}$ Emission-Empirical Analysis from Decomposition and Dynamic Panel Estimation[J]. Journal of Shanxi Finance and Economics University, 2012(1). (In Chinese).

[6] XU Guo-quan , LIU Ze-yuan , JIANG Zhao-hua. Decomposition Model and Empirical Study of Carbon Emissions for China, 1995 - 2004[J]. CHINA POPULATION RESOURCES AND ENVIRONMENT 2006, 16(6). (In Chinese).
[7] HONG Ye-ying. Relation between Agricultural NPS Pollution and Economic Growth: By Using Environmental Kuznets Curve[J]. Journal of Yangtze River Scientific Research Institute, 2014, 1(1). (In Chinese).

[8] BIRDSALL N. Another look at population and global war-ming: Population, health and nutrition policy research[C]. Working Paper, Washington, DC: World Bank, WPS1020, 1992 . (In Chinese).

[9] Jiang, L, Hardee, K. How Do Recent Population Trends Matter to Climate Change? Population Action International, 2009 (In Chinese).

[10] CHEN Jing. The Effect of Population Oncarbon Emissions[J]. NORTHWEST POPULATION JOURNAL, 2011(2). (In Chinese) 